\title{
Factors Affecting the Economic Development and Urbanization of Mountain Area--Taking Yunnan Provinces as an Example
}

\author{
Tian Renqu ${ }^{1, a}$, Yang Zisheng ${ }^{2, b,}$, \\ ${ }^{1}$ Institute of economics, Yunnan University of Finance and Economics, Kunming, Yunnan, China \\ 2 Institute of Land \& Resources and Sustainable Development, Yunnan University of Finance and \\ Economics, Kunming, Yunnan, China \\ a goldfishgogo@163.com, b yangzisheng@126.com
}

Keywords: urbanization; economic growth; regional development; Yunnan

\begin{abstract}
Urbanization of mountain area is an important part of a country's economic development. This paper use a data set of province-level per capita gross domestic product and socio-economic data, as well as statistical methods panel OLS to explore the determinants of growth at the district level in 2009 and 2014. The result shows that population density have some impacts on the growth, development level of market access and the second and third industries are the main factors affecting the economic development of Yunnan. In the process of urbanization development in Yunnan, we should firstly fully exploited geographical advantage and unique resource conditions of each region to promote the development of the second and third industries; secondly improving the transportation infrastructure construction of facilities, and promote trade circulation between regions; thirdly strengthen the construction of regional central cities, and improve the economic radiation of the central cities.
\end{abstract}

\section{山区城镇化经济发展影响因素初探一一以云南为例$$
\text { 田人渠 }{ }^{1, a}, \text { 杨子生 } 2, \mathrm{~b},{ }^{*}
$$ \\ 1 云南财经大学经济学院, 昆明, 云南, 中国 \\ 2云南财经大学国土资源与持续发展研究所, 昆明, 云南, 中国 \\ a goldfishgogo@163.com, ${ }^{b}$ yangzisheng@126.com}

关键词：城镇化；经济增长；区域发展；云南

中文摘要. 山区城镇化是国家城镇化建设的重要组成部分, 为探讨山区城镇化经济发展的影响 因素, 本文以云南省的 16 个州市作为经济发展的研究对象, 运用经济增长模型分析 2009 年 和 2014 年的经济社会数据以揭示在地区层面决定经济增长的因素。研究结果显示: 人口密度 对有云南城镇化经济发展有一定影响, 市场准入程度和二三产业的发展水平是影响云南城镇 化经济发展的主要因素。为实现区域协调发展, 在未来云南城镇化进程中应发挥各区域自身 的地理位置优势, 利用独特的资源条件推动二三产业的发展; 完善交通运输基础设施建设, 促进各区域间的贸易流通；加强区域中心城市建设，提高中心城市的经济辐射作用。

1. 引言

城镇化是人口和产业要素向收益较高的城镇地区流动的过程，大部分的经济增长如技术 
采纳和资本积累均发生在城市。在我国现代化进程中，山区肩负着生态、国防安全保障等重 大战略责任，是我国城镇发展的主要分布区 ${ }^{[1]}$ 。近年来伴随着中央政府的一系列宏观经济与 产业升级战略, 工业化和城市化的发展也迅速改变了山区的自然与人文景观, 包括农村人口 向城市迁移、房地产的发展等 ${ }^{[2]}$ 。而目前学者主要集中于以东部沿海地区和中国整体的视角 来研究城镇化的发展, 较少关注到西部山区经济发展的问题 ${ }^{[3]}$ 。

云南主要以山地经济为主, 相比平原地区, 山区经济发展面临更为复杂的因素。本文运 用经济增长理论, 对云南省各区域经济增长的现状和经济发展的影响因素进行研究分析。本 文研究的主要问题有: 目前云南区域经济受地理位置、产业结构、人口密度、学龄儿童入学 率等因素的影响的程度如何, 并对缩小区域经济差距提出政策建议。本文通过对这些问题的 研究, 揭示云南区域经济差异的特点以及成因, 为区域健康持续发展制定相关政策提供合理 依据。

\section{2. 相关文献综述}

近年来，国内外学者对区域经济发展的研究主要集中在经济发展差异的时空演变特征与 影响因素方面。Combes (2011) ${ }^{[4]}$ 认为区域的富有程度具有空间扩散的现象, 即那些接近富 有地区的区域不可能是很贫穷的地区, 这种现象在国家内部和国家之间都存在。曾湘泉 (2013) [5]对中国各省及经济区城镇吸纳农村劳动力效率的研究发现, 我国城镇单位在吸纳农村劳动力 的效率上存在东南高、西北低的阶梯状地理差异性。陈斌开（2013） [6]利用 1978-2008 年中国 省级面板数据研究发现, 中国城乡收入差距在经济发展过程中呈现出先下降、后上升的U型 规律。刘彦随和杨忍（2012） [7]运用样带、地统计、地理探测器等多种研究方法对中国县域 城镇化的时空特征及形成机理进行研究, 研究表明 2000 年以来中国县域差异逐渐缩小, 固定 资产投资、离中心城市距离、人口密度等因素也影响县域城镇化水平及发展过程。林毅夫、 孙久文（2015） ${ }^{[8]}$ 以及 Octasiano（2016） [9]等人的研究发现，经济特区发展战略、金融支持 一系列政府的偏向性政策是中国区域间收入差距扩大的重要原因。部分学者如邓伟（2013） [10]、余凤龙 (2014) [11]等研究城镇化与旅游经济发展相互作用的问题, 得出结论: 城镇化能 间接促进旅游经济增长。杨志海 (2013) ${ }^{[12]}$ 的研究发现县域城镇化的推进能显著缩小城乡收 入差距, 而缩小城乡收入差距反过来也有利于提高城镇化水平。然而, Brückner（2012）[13]通 过估计农业部门的规模和人均生产总值（GDP）的增长对城市化率的影响, 认为城市化率的 增加对人均 GDP 增长有显著的负向影响。吴先华 (2011) ${ }^{[14]}$ 对城镇化、市民化与城乡收入差 距之间的内在关系进行了多重检验，结果显示城镇化在短期水平扩大了城乡差距。

国内外关于区域经济差异的研究有很多, 由于各地区的实际情况不同, 各学者采用的研 究方法、时间阶段不同, 得出的研究结论也不一致。目前的研究还未深入探讨地理区位对区 域经济差异变化的影响, 同时专门针对云南省区域经济差异进行系统分析的文献还较少。因 此本文将两地间的最短公路距离来反映区域间运输成本上的差异, 并量化测算各要素对云南 省区域经济增长的贡献，探索区域地理位置、交通建设和非农产业比重对云南经济发展的影 响，为加快云南区域经济转型、促进区域经济整体协调发展提供有益的对策建议。

\section{3. 研究区概况与数据来源}

\section{1 研究区概况}

云南偏居祖国西南, 集边疆、山区、少数民族、贫困为一体, 其中山地高原占全省土地 总面积的 $94 \%$ ，坝区仅占 $6 \%$ 。云南作为一个农业大省，随着改革开放的发展区域经济得到 了快速增长, 产业结构也在逐步改变。2009 年第一产业占云南地区人均生产总值（GDP）的 比重为 $17.3 \% ， 2014$ 年下降至 15.5\%。第二产业占 GDP 的比重从 2009 年的 $41.9 \%$ ，略降至 2014 年的 $41.2 \%$ 。第三产业占 GDP 的比重从 2009 年的 $40.8 \%$ ，上升至 2014 年的 $43.3 \%$ 。 
可看出目前云南省的经济主要以第三产业为主导, 非农产业在国民生产总值中的比重逐年增 加, 一定程度上加快了城市化的进程。本文对影响云南人均 GDP 增长的经济和地理位置等因 素进行深入分析，可为减小区域间经济差异提供决策参考。

\section{2 数据来源}

本文以西部地区的云南省为例进行分析, 主要选择云南省 16 个州、市样本的上述变量指 标, 其中人均地区生产总值取其自然对数, 二三产业增加值占生产总值比重、人口密度、学 龄儿童入学率等指标数据均来源于对应年份的《云南省统计年鉴》和《中国区域经济统计年 鉴》整理而成。考虑到以上数据的完整性和比较性, 时间选取上主要参考云南经济金融发展 中具有代表性的 2009 年和 2014 年 2 个时间节点进行对比。

\section{4. 变量相关性分析及实证结果}

地理位置虽然不能直接影响经济发展，但可以通过其对商品流通、生产要素的作用来间 接影响人均生产总值 ${ }^{[15]}$ 。相比直线距离, 实际距离是两地间运输成本更合理的衡量标准。本 文将两地间的公路距离来反映区域间运输成本上的差别。为了实现这一点, 本文将每个地区 的人均生产总值与区域的地理位置和经济特征等数据结合起来研究。

在构建地理距离与经济增长关系的计量模型时，笔者主要参照 $\operatorname{Das}(2015)^{[16]}$ 在经济增长 模型理论的基础上加入了贸易开放度变量的研究方法, 使用两地间最短公路距离反映运输成 本, 将市场准入、非农产业比重、人口密度、学龄儿童入学率等变量直接列入回归方程中用 以作为解释变量, 人均地区生产总值的增长则作为被解释变量。在加入了云南省区域特征变 量后的回归方程如下:

$$
\ln y_{i}(t)-\ln y_{i}(0)=\alpha_{0}+\alpha_{1} \ln y_{i}(0)+\alpha_{2} M A+\eta X_{i}+\varepsilon_{i}
$$

本文的市场准入指一个区域允许另一区域的商品、人力与资金参与区域内市场的程度, 贸易量取决于所有市场交易成本的加权平均。市场准入水平被定义为:

$$
M A=\sum_{j \in N} w_{j} d_{i, j}
$$

其中 $d_{i, j}$ 为区域 $i$ 到区域 $j$ 的最短公路距离, $w_{j}=Y_{j} / Y, Y_{j}$ 为区域 $j$ 的生产总值; $Y$ 为云 南地区的生产总值; $N$ 为总的区域数量。

方程 (1) 中的 $\ln y_{i}$ 为 $t$ 期人均生产总值的对数形式, $\ln y_{0}$ 为初期人均生产总值的对数形 式, 为常数项, $M a$ 为市场准入, 包括二三产业增加值占生产总值比重、小学学龄儿童入学 率、人口密度等。 $\varepsilon$ 为误差项, 包括该地区的气候条件和资源禀赋等。表 1 为以上变量的描 述性统计。 
表 1 描述性统计

\begin{tabular}{|c|c|c|c|c|c|c|}
\hline 变量 & & 均值 & 标准差 & 最小值 & 最大值 & 样本数 \\
\hline \multirow{3}{*}{$\begin{array}{c}\text { 人均 GDP } \\
\text { 增长率 }\end{array}$} & 整体 & \multirow[t]{3}{*}{0.046} & 0.017 & -0.013 & 0.075 & $\mathrm{~N}=32$ \\
\hline & 组内 & & 0.012 & 0.013 & 0.065 & $\mathrm{n}=16$ \\
\hline & 组间 & & 0.012 & 0.021 & 0.072 & $\mathrm{~T}=2$ \\
\hline \multirow{3}{*}{$\begin{array}{c}\text { 初始人均 } \\
\text { GDP }\end{array}$} & 整体 & \multirow[t]{3}{*}{4.179} & 0.247 & 3.71 & 4.72 & $\mathrm{~N}=32$ \\
\hline & 组内 & & 0.185 & 3.895 & 4.565 & $\mathrm{n}=16$ \\
\hline & 组间 & & 0.168 & 3.974 & 4.384 & $\mathrm{~T}=2$ \\
\hline \multirow{3}{*}{$\begin{array}{c}\text { 市场准入 } \\
\text { 水平 }\end{array}$} & 整体 & \multirow[t]{3}{*}{4.527} & 4.143 & 0.637 & 17.773 & $\mathrm{~N}=32$ \\
\hline & 组内 & & 4.204 & 0.638 & 17.532 & $\mathrm{n}=16$ \\
\hline & 组间 & & 0.244 & 3.767 & 5.287 & $\mathrm{~T}=2$ \\
\hline \multirow{3}{*}{$\begin{array}{l}\text { 二三产业 } \\
\text { 增加值占 }\end{array}$} & 整体 & \multirow[t]{3}{*}{79.29} & 7.983 & 65.154 & 95.11 & $\mathrm{~N}=32$ \\
\hline & 组内 & & 7.947 & 67.54 & 94.428 & $\mathrm{n}=16$ \\
\hline & 组间 & & 1.616 & 76.51 & 82.07 & $\mathrm{~T}=2$ \\
\hline \multirow{3}{*}{$\begin{array}{c}\text { 学龄儿童 } \\
\text { 入学率 }\end{array}$} & 整体 & \multirow[t]{3}{*}{99.57} & 3.56 & 95.86 & 113.38 & $\mathrm{~N}=32$ \\
\hline & 组内 & & 3.44 & 96.05 & 111.18 & $\mathrm{n}=16$ \\
\hline & 组间 & & 1.12 & 97.25 & 101.89 & $\mathrm{~T}=2$ \\
\hline \multirow{3}{*}{ 人口密度 } & 整体 & \multirow[t]{3}{*}{118.6} & 72.967 & 17.1 & 307 & $\mathrm{~N}=32$ \\
\hline & 组内 & & 73.982 & 26.8 & 299 & $\mathrm{n}=16$ \\
\hline & 组间 & & 5.234 & 103.906 & 133.21 & $\mathrm{~T}=2$ \\
\hline
\end{tabular}

接下来利用式（1）进一步估计云南省经济增长的影响因素。表 2 报告了回归方程（1） 式的面板最小二乘估计结果。

表 2 加入不同控制变量的实证结果

\begin{tabular}{cllll}
\hline & $(1)$ & $(2)$ & $(3)$ & $(4)$ \\
\hline 人均 GDP & $-0.039^{* *}$ & $-0.031^{*}$ & $-0.039^{* *}$ & $-0.028^{*}$ \\
& $(-2.709)$ & $(-1.074)$ & $(-2.690)$ & $(-2.454)$ \\
市场准入水平 & $0.016^{*}$ & $0.007^{* * *}$ & 0.015 & $0.008^{* *}$ \\
& $(1.820)$ & $(-3.267)$ & $(1.630)$ & $(-2.255)$ \\
二三产业增加值 & & $0.485^{* * *}$ & & $0.484^{* * *}$ \\
& & $(10.117)$ & & $(9.378)$ \\
学龄儿童入学率 & & & & 0.024 \\
& & & & $(-0.508)$ \\
人口密度 & & & $0.000^{*}$ & $0.000^{*}$ \\
& & & $(-1.913)$ & $(-0.894)$ \\
截距 & $0.140^{*}$ & $0.069^{* *}$ & $0.173^{*}$ & $0.077^{*}$ \\
样本数 & $(1.911)$ & $(2.302)$ & $(2.037)$ & $(1.520)$ \\
调整 $\mathrm{R}^{2}$ & 32 & 32 & 32 & 32 \\
\hline & 0.423 & 0.934 & 0.434 & 0.938 \\
\hline
\end{tabular}

注: $* * *$ 、**和*分别为 $1 \% 、 5 \%$ 和 $10 \%$ 的显著性水平。

本文使用固定效应来控制各时间段之间的动态差异。其中初始人均生产总值这一变量的 系数均为负值, 并且在 $5 \%$ 或 $10 \%$ 的显著水平下显著, 满足条件收玫, 表明在给定的条件下 区域经济会趋于稳态水平。组合（1）中，我们仅观察市场准入程度和初始人均生产总值的对 数值两个变量。估计结果表明, 市场准入程度和初始人均生产总值的估计系数在 $5 \%$ 或 $10 \%$ 的显著水平下显著。从而市场准入程度和初始人均生产总值越大的地区, 其经济增长率也越 高。在方程(2)和(3)中分别加入了二三产业增加值占生产总值比重和人口密度变量。最后, 在 
方程(4)中加入了所有变量, 可看出变量 $\mathrm{y}$ 和 $\mathrm{ma}$ 的符号或显著性的变化不大, 结果仍然较稳 定。其中人口密度变量在 $10 \%$ 的水平下显著, 说明了人口密度对云南经济增长有一定影响, 这一结论与之前的文献研究结果也是一致的。二三产业增加值占生产总值比重和市场准入变 量分别在 $1 \%$ 和 $5 \%$ 的水平下显著, 说明市场准入程度和非农产业的发展对云南经济增长有重 要影响。组合(4)中, 虽然各区域学龄儿童入学率变量的符号与理论一致, 却没有显著性。有 可能是由于近年来随着全国教育事业的发展, 义务教育普及成效显著, 云南省各区域的学龄 儿童入学率相差不是很大。

\section{5. 结论和政策建议}

通过对云南 16 个区域的经济增长的影响因素及特征分析, 得到如下主要结论:

从实证结果来看，云南地区的经济增长主要依靠非农产业的发展来推动，因此要充分发 挥其他州市的地理位置优势和独特的资源来发展工业化和城镇化。同时也要注意到在产业升 级过程中资源环境恶化, 社会矛盾增大的风险, 可大力发展旅游、文化等产业来提高就业机 会和人均收入。虽然农业不是主导经济增长的产业, 但其仍然是关系到国计民生的基础产业, 直接关系到第二第三产业的健康发展。各个州市特别是偏远山区, 可结合自身的农业条件, 发展有机农业、旅游农业、能源农业等，促使农业从传统经营向多元化经营转变。

完善交通运输基础设施建设，促进各区域间的贸易流通。“要想富，先修路”，对于山区 的经济发展更是如此。交通运输网络的完善和服务水平的提高, 有助于经济运行效率的提升。 物流成本的降低, 也会带动汽车、治金、电商、旅游、房地产等相关产业的发展, 贸易程度 的提高会让更多的农民能在非农产业中有就业机会，从而加快城镇化建设，保持云南经济的 持续、稳定、协调发展。

加强区域中心城市的建设，提高中心城市的经济辐射作用。目前云南的州市中只有昆明、 曲靖为人口 400 万以上的中心城市, 从周边鲁甸、新平等县域的经济发展来看, 云南省中心 城市的辐射作用还不是很明显。首先, 中心城市群构成了区域经济活动网络的主要连接点, 对经济发展起主导作用。第二, 中心城市群对于出口货物和劳动力能够提供更多的便利和更 高的收入。因此, 通过这种关联中心城市群也惠及周边地区。

\section{References}

[1] Zheng, Jc., Duan, G. Mountain theory of urbanization development. Inquiry into Economic Issues, vol. 12(7), pp. 25-30, 2013.

[2] Long, H. L., Liu, Y. S., Li, X. B., \& Chen, Y. F. Building new countryside in China: a geographical perspective. Land Use Policy, vol. 27(2), pp. 457-470, 2010.

[3] Gao, Y., \& Ma, Y. What is absent from the current monitoring: idleness of rural industrial land in suburban Shanghai. Habitat International, vol. 49, pp.138-147, 2015.

[4] Combes, P.-P., Lafourcade, M., Competition, market access and economic geography: Structural estimation and predictions for France. Journal of Economic Geography, vol. 41(6), pp. 243-271, 2011.

[5] Zeng,Xq., Chen,Lw., Yang, Ym,. Urbanization, industrial structure and rural labor transfer absorption efficiency, Journal of Renmin University of China, vol. 4, pp. 36-46, 2013.

[6] Chen, Bk., Lin, Yf,, Development strategy, urbanization and the ural-urban income disparity in China, Social Sciences in China, vol.4(26), pp. 81-102, 2013.

[7] Liu, Ys., Yang, R., The Spatial Characteristics and Formation Mechanism of the County Urbanization in China, Acta Geographica Sinica, vol. 67, pp. 1011-1020, 2012. 
[8] Sun, Jw., Zhou, Yl., Urban - rural Disparity, Labor Migration and Urbanization, Economic Review, vol. 4(2), pp. 29-40, 2015.

[9] Octasiano M. Valerio Mendoza. Preferential policies and income inequality: Evidence from Special Economic Zones and Open Cities in China. China Economic Review, vol. 40, pp. 228-240. 2016.

[10]Deng, W., Tamd, W., General Directions and Countermeasures for Urbanization Development in Mountain Areas of China, Journal of Mountain Science, vol. 31, pp. 168-173, 2013.

[11]Yu, Fl., Huang, Zf., Cao, Fd., etc. Influence of China's Urbanization on Tourism Economic Development, Journal of Natural Resources, vol. 29, pp. 1297-1309, 2014.

[12] Yang, Zh., Liu, Xf.,Wang, Yp., Can Urbanization of County Narrow Gap of Urban-Rural Income?_Empirical Test Based on Panel Data of 1523 Counties (Cities), Journal of Huazhong Agricultural University(Social Sciences Edition), vol. 67, pp. 1011-1020, 2013.

[13]Brückner, M., Economic Growth, size of the agricultural sector, and urbanization in Africa. Journal of Urban Economics, vol. 71, pp. 26-36, 2012.

[14]Wu, Xh., Relationship among urbanization, citizenization and urban-rural income inequality, Scientia Geographica Sinica, vol. 31, pp. 68-73, 2011.

[15]Redding, S., \& Venables, A. J. Economic geography and international inequality. Journal of international Economics, vol. 62(1), pp.53-82, 2004.

[16]Das, S., Ghate, C., Robertson, P.E., Remoteness, Urbanization, and India's Unbalanced Growth. World Development, vol. 5(66), pp.572-587, 2015. 